ISSN 1112-9867

Available online at $\quad$ http://www.jfas.info

\title{
SIMULATION OF MUNICIPAL SOLID WASTE ROUTE OPTIMIZATION BY DIJKSTRA'S ALGORITHM
}

\author{
K. Norhafezah ${ }^{1 *}$, A. H. Nurfadzliana ${ }^{1}$ and O. Megawati ${ }^{2}$ \\ ${ }^{1}$ Faculty of Civil Engineering, Universiti Teknologi MARA, 40450 Shah Alam, Selangor, \\ Malaysia \\ ${ }^{2}$ Academy of Language Studies, Universiti Teknologi MARA, 40450 Shah Alam, Selangor, \\ Malaysia
}

Published online: 17 October 2017

\begin{abstract}
This study simulated the routes of a municipal solid waste collection by a mathematical model of Dijkstra's Algorithm. Its aim was to achieve route optimization by shortening the distance travelled by the municipal solid waste collectors. The waste collectors usually face difficulties in selecting the most cost-efficient routes to collect wastes due to the presence of multiple collection points. It is observed that unsystematic collection route planner travelled by the waste collectors increases the time and cost of waste management. Thus, to reduce the time and cost of collection, it was hypothesized that the routes taken by the waste collectors be shortened to optimize the cost-effectiveness. This study again hypothesized that employing a mathematical model of Dijkstra's Algorithm would be able to demonstrate the route optimization.
\end{abstract}

Keywords: collection routes; Dijkstra's Algorithm; municipal solid waste; route optimization; urban area.

Author Correspondence, e-mail: norhafezahkasmuri@salam.uitm.edu.my doi: http://dx.doi.org/10.4314/jfas.v9i5s.52 


\section{INTRODUCTION}

The rapid increase of the unwanted solid waste is a critical concern in most countries in the world as it poses severe risks to public health. Malaysia, a country on transition with rapid growth of urbanization, is no exception. In 2008, 23,000 tons of waste was recorded to have been produced each day in this country, with less than $5 \%$ of them being recycled. The unrecorded generation of wastes might have increased this volume. In Selangor, one of the states in Malaysia, waste generated in 1997 was over 3000 tons/day and the amount is expected to rise to 5700 tons/day in the year of 2017 . An alarming $19 \%$ of these wastes end up in drains, which then cause flash floods and drainage blockage. In addition, if not properly treated, they will pollute environment, which in turn affect human health.

Municipals, authorities responsible for the cleanliness of cities and neighbourhoods, face huge tasks in collecting the wastes as population and urbanization expand. The undertaking is compounded by the steady increase of waste management cost each year. Hence, municipals and waste collectors are always in search of the most optimized wayin their planning and operation to collect wastes.

In this case, solid waste is defined as generation of undesirable substances which is left after they are used. It can also be defined as unwanted items in the solid state derived from any activities and discarded by society [1]. Further, there are many types of solid waste, which can be generally classified into three. The first is any materials that can be recycled or accumulated, which can be useful objects but no longer wanted such as scrap metal, glass, cans, paper, plastics, wood and similar materials [2]. The second type is the ones which can be segregated for disposal or burned for energy recovery, reclaimed and accumulated speculatively. This include the green wastes, the compost and yard clippings, which are collected separately from true garbage to be processed into compost and returned to the earth [3]. The third is the unwanted or discarded material that is abandoned and inherently waste-like [1]. These materials require care in handling as they could also be toxic and potential to contaminate the environment. Another is electronic waste, which is a growing problem in many industrialized nations.

A good system of solid waste collection is an important component for an effective solid waste management. Hence, to design and develop an appropriate collection route plan is 
crucial. This is to ensure an efficient collection path for any municipal in its effort to reduce expenditure of solid waste management system. This is especially important as budgets for waste collection often suffers more cuts than others in times of economic slowdown. Hence to ease its organization, management and planning, according to [4] there must be a new system to improve the "existing system and bring the possible reforms by adopting measures through the introduction of innovative and effective solutions".

In cities, solid wastes are generally generated from residential areas, commercial and industrial facilities. As such the collection of commingled and separated solid waste is demanding due to the concentration of population and human activities. As the dispersal and quantity of waste generation increases, the logistics of collection grow more complex as well [5]. These problems have always existed but they have become more critical as labour cost rises, where of the total amount of money spent for collection, transportation, and disposal of solid wastes, approximately 50 to 70 percent was spent on the collection phase or process [6]. Therefore, there's a need to improve the collection operation as it can affect the overall cost and time of solid waste management (SWM). One of the ways to improve waste collection is to guide the garbage collectors to select the shortest paths during the collection.

The municipals generally will prepare a collection route planner for their garbage collectors. Firstly, the municipal will study the existing policies and regulations related to items such as the point of collection and frequency of collection. The existing system characteristic like the crew size and vehicle types then is coordinated [7]. The routes are planned out so that they begin and end near arterial streets, using topographical and physical barriers as route boundaries. Routes are also laid out in the manner that the last container to be collected on the road is located nearest to the disposal sites.

It has been a practice that waste is collected as early as possible in the day. And large quantities of wastes collection points serviced during the first part of the day. Scattered pickup points that receive the same collection frequency should be serviced during one trip or on the same day [8].

Therefore, to address the complexity of waste collection, in this study, the collection routes were simulated using a mathematical model of Dijkstra's algorithm. The shortest path algorithm in the graph theory is considered as a based effective algorithm to solute vehicle 
routing [9]. It is known that the basic use of Dijkstra's algorithm is a graph search algorithm that solves the single-source shortest path problem for a graph with nonnegative edge path costs, producing a shortest path tree as shown in Fig. 1 [10].

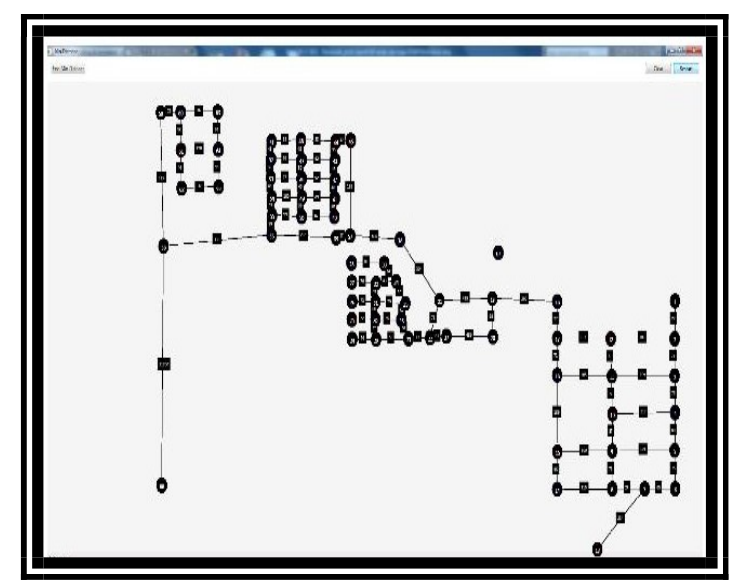

Fig.1. Example of analysis process by Dijkstra's Algorithm

In particular, this research then was to explore the shortest paths to be travelled by the waste collectors among the source labels, the waste dumps, the point label and the disposal sites. It thus attempted to reduce the length of the present routes to assist the waste collectors and the municipal concerned in minimizing the cost of the waste management.

\section{MATERIAL AND METHODS}

The simulation was conducted for the solid waste collection of Section 7, Shah Alam, Selangor, Malaysia in June, 2016. Shah Alam is a city and the state capital of Selangor, Malaysia, with estimated population of 650,000 people. It is managed by Shah Alam City Council (MBSA). Shah Alam consists of 25 sections of which Section 7, the selected area for the study, contains four main roads. The roads are Persiaran Permai, Persiaran Bestari, Persiaran Masjid and Persiaran Kayangan. These roads run through the main areas which are well-planned and densely but populated (Fig. 2). 


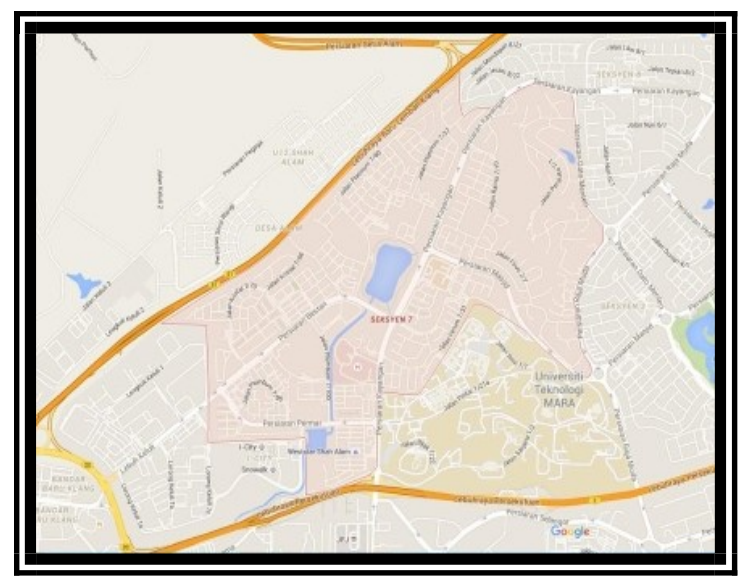

Fig.2. The boundary of Section 7, Shah Alam, Selangor

The municipal solid waste management of this study area was under the supervision of the MBSA. Due to the large coverage area of Section 7, the MBSA divided the collection into three (3) zones and managed by three (3) companies. The MSW generated in the first zone was collected by Introvision Resources SdnBhd, the second zone by Aiman Platinum SdnBhd, and the third, JelapangGemilang Enterprise. For ease of reading Introvision Resources SdnBhd was labeled Contractor A, Aiman Platinum SdnBhd labelled Contractor B and Jelapang Gemilang Enterprise, Contractor C.

To begin the simulation, raw data which were the Municipal Solid Waste (MSW) Collection Routes in Section 7, Shah Alam were obtained from the MBSA, and three waste collectors. The raw data obtained were the: a) Study area boundary; (b) Name of the roads, and (c) Municipal solid waste collection schedule.

These MSW Collection Routes were digitized in the Google Earth. These digitized data were limited to only the name of the collection roads and schedule of collection. They did not consider other factors such as land elevation or traffic density. In order to digitize the collection roads in the Google Earth and Autocad software and to simplify the analysis, the point where the roads begin were considered the collection points. The sequence of the collection of MSW was assumed following the collection schedule given by the MBSA.

There were three roads considered in the simulation. Fig. 3 shows that the roads travelled by three contractors are marked by three colours. The roads travelled by Contractor A are in yellow, roads of Contractor B red while Contractor C, blue. 


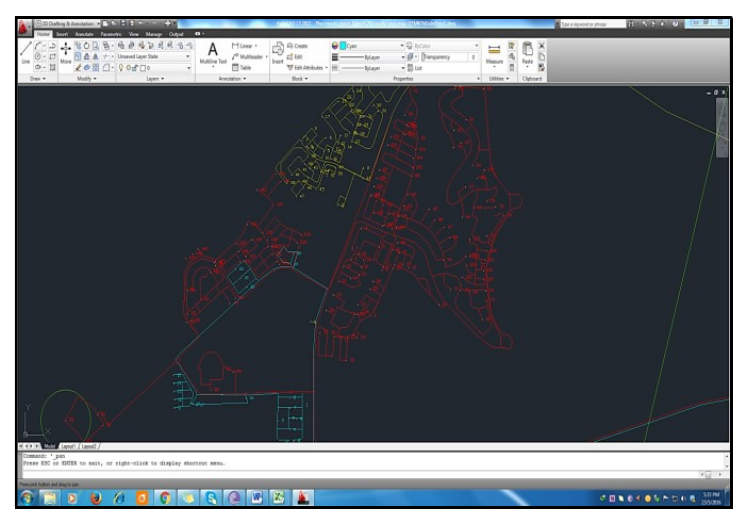

Fig.3. Polylines of the collection routes in the AutoCAD LT 2011 software

Due to the lack of detailed data and information from the MBSA and its contractors, the roads that were listed in the schedule were assumed as the collection points. Each road was marked to estimate the distance of the routes that connected the collection points. Then lastly, the total distance of the existing routes was calculated.

The next step was that these routes were identified by comparing the images from the Google Earth and those of the drawings of the AutoCAD. The distance and names of the roads were inserted into the attribute table. After that, geo-referencing steps were conducted by overlapping the Google Earth image and road layers to ensure the road names are identified similar [6].

After the collection routes were digitized in the Google Earth, the map was transferred to the AutoCAD software to create the polylines of the collection routes (that had been digitized earlier). Polylines then were drawn following the digitized roads in the map (Fig. 3). They were created to calculate the total distance of the actual municipal solid waste collection routes. The distance of the digitized routes was compared between that of the Google Earth and the AutoCAD software to obtain the digitized error.

Then, the distance between these collections points was analysed by Dijkstra's Algorithm. The basic idea of Dijkstra Algorithm is to explore the shortest path from the source point to the outside point gradually. The algorithm exists in many variants; Dijkstra's original variant found the shortest path between two nodes, but more common variant fixes a single node as the 'source' node and finds shortest paths from the source to all other nodes in the graph, 
producing a shortest path tree.

A tentative distance value was allocated to every in node of whose initial is set to zero while the others, infinity. A set of visited nodes was started with the initial node. The current node considers all of its unvisited neighbours and calculate (distance to the current node) + (distance from current node to the neighbour). If this was less than their current tentative distance, it was replaced with a new value. After all the neighbours of the current node were inserted, the current node was marked and removed from the unvisited set. If the destination node had been marked visited, the algorithm was then finished. "The unvisited nodes are marked with the lower value of the tentative distance that is then is set as the next 'current node' and the same cycle is repeated" [10].

In order to optimize the collection routes, Dijkstra's Algorithm software was used to calculate the shortest distance. In choosing the optimized routes, the length of the routes were considered a vital factor. The MSW collection points that had been digitized in the AutoCAD software were copied onto the Dijkstra's Algorithm software. The distance between the collection points were inserted by clicking the two (2) desired nodes which were obtained from the digitized map in AutoCAD software.

The shortest distance between two (2) selected nodes was automatically calculated by the clicking button 'Find Minimum Distance' at the upper left-side. The amount of shortest distance was shown at the bottom left, which simplified the calculation to obtain the shortest distance.

\section{RESULT AND DISCUSSION}

The results showed that the Dijkstra's Algorithm had reduced the routes travelled by the three waste collectors. Respectively, Table 1 shows the summary of reduced Contractor A's routes by $17 \%$, Contractor B's routes $33 \%$, and Contractor C's, $12 \%$. 
Table 1. Difference between the actual and optimized routes of contractor A, B and C

\begin{tabular}{lccc}
\hline Contractor & $\begin{array}{c}\text { Distance of Actual } \\
\text { Routes (m) }\end{array}$ & $\begin{array}{c}\text { Distance of Optimized } \\
\text { Routes (m) }\end{array}$ & $\begin{array}{c}\text { Difference } \\
(\mathbf{m})\end{array}$ \\
\hline Contractor A & 26,708 & 22,259 & $4,449(17 \%)$ \\
\hline Contractor B & 87,773 & 58,521 & $29,522(33 \%)$ \\
\hline Contractor C & 20,754 & 18,281 & $2,473(12 \%)$ \\
\hline
\end{tabular}

\section{Result 1: The reduction of Contractor A's routes $-\mathbf{1 7 \%}$.}

The MSW collection routes digitized in the AutoCAD software from the Google Earth of Contractor A was 26,708 meters before the simulation. Fig. 4 shows the simulation of the shortest collection routes taken by Contractor $\mathrm{A}$ in the form of the sequence of the collection points being changed. The simulated MSW collection route was designed with the total of 51 collection points and one (1) Transfer Station without having any collection point unattended. They were change to as follows: $1>38>2>3>50>51>52>46>47>48>49>39>$ $40>41>42>43>44>45>9>7>8>4>5>6>10>11>16>15>14>12>13>$ $17>23>22>21>20>19>18>25>27>26>24>34>29>30>32>31>33>35>$ $36>37>$ Transfer Station.

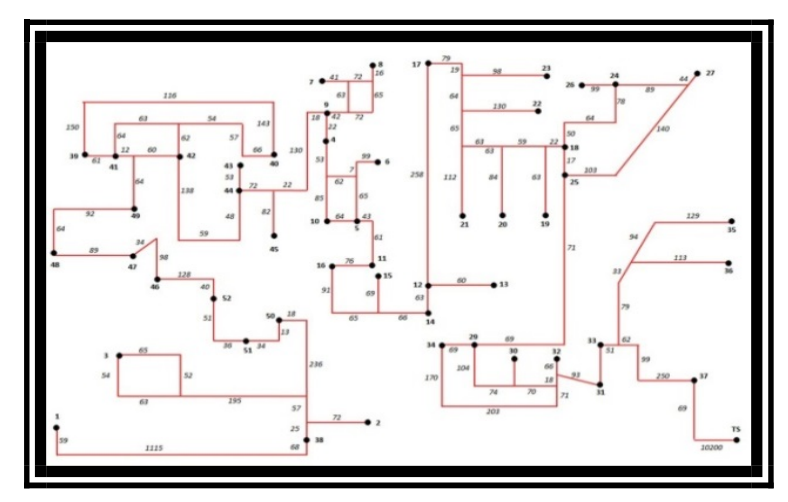

Fig.4. Distance of MSW collection routes of Contractor A by Dijkstra's Algorithm

Fig. 5 shows the shortened routes (black lines) which are shorter than the actual ones (grey lines). The calculation for the change of percentage (\%) in the shortening of routes is as follows: 
Wo of Minimizations $\frac{\text { Distance Actual - Distance Optimired }}{\text { Distance Actual }} \times 100$

\$6 of Minimization $\frac{267 \mathrm{cg} m-22269 \mathrm{~m}}{26708 \mathrm{~m}} \times 100$

96 of Minimiration: $17 \%$

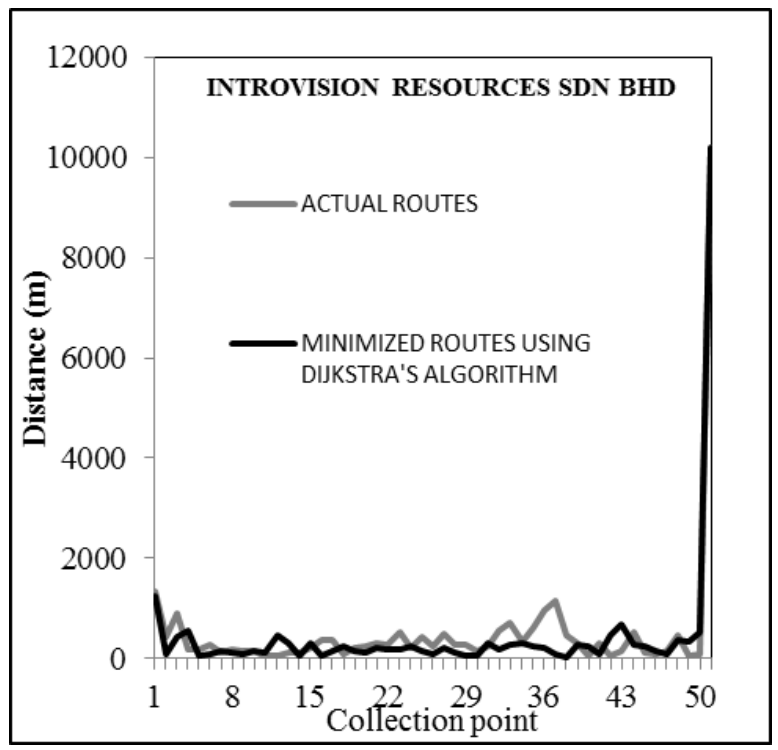

Fig.5. The difference between the actual and the shortened routes of Contractor A

\section{Result 2: The reduction of Contractor B's routes}

The AUTOCAD digitized collection routes was 87,773 meters for the MSW collection routes before minimization. The collection routes of Contractor B are also being minimized by Dijkstra's Algorithm and the shortest distance is 58,521 meter. Fig. 6 shows the sequence of the collection points also being changed to $51>52>53>51>56>57>55>39>45>44>$ $48>49>50>47>46>43>41>40>42>145>150>149>148>146>147>129>$ $130>131>133>132>128>140>142>143>141>144>135>136>137>138>$ $134>139>38>37>36>31>30>29>7>28>32>34>33>6>26>27>25>24>$ $22>23>16>17>18>19>20>21>5>2>14>9>12>13>4>11>10>8>15>$ $1>3>111>110>119>115>118>117>112>116>113>114>109>108>107>$ 
$106>105>100>104>99>103>98>97>102>101>96>92>91>93>90>82>$ $83>84>95>94>85>86>87>89>88>77>78>79>81>80>76>120>123>$ $122>124>125>127>126>121>74>73>71>72>68>69>70>66>67>65>$ $61>64>63>75>62>59>60>58>$ Transfer Station. The MSW collection route was designed with the total of 150 collection points and one (1) Transfer Station with no collection point unattended.

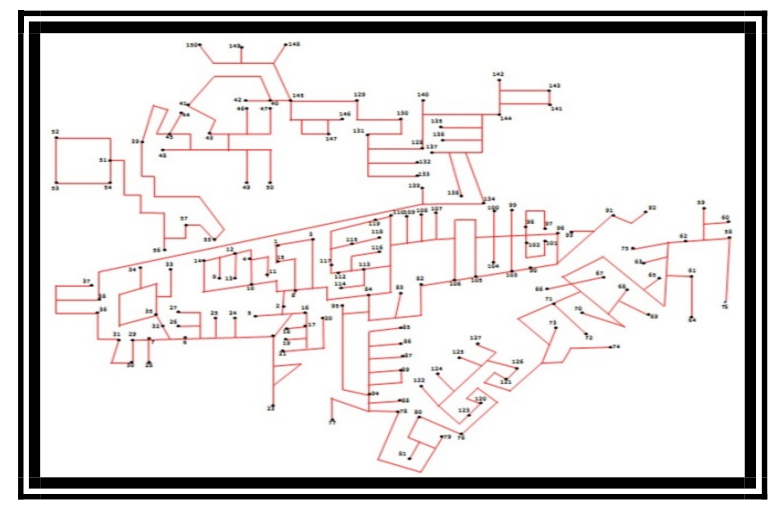

Fig.6. Shortest distance of MSW collection routes of Contractor B by Dijkstra's Algorithm

Fig. 7 shows the difference between the actual municipal solid waste collection routes distance and minimized routes of Contractor B. The actual routes are shown by grey lines while the minimized in black. The graph shows that the grey line was higher compared to the black line indicating that the actual collection routes is longer than the one simulated by the Dijkstra’s algorithm. 


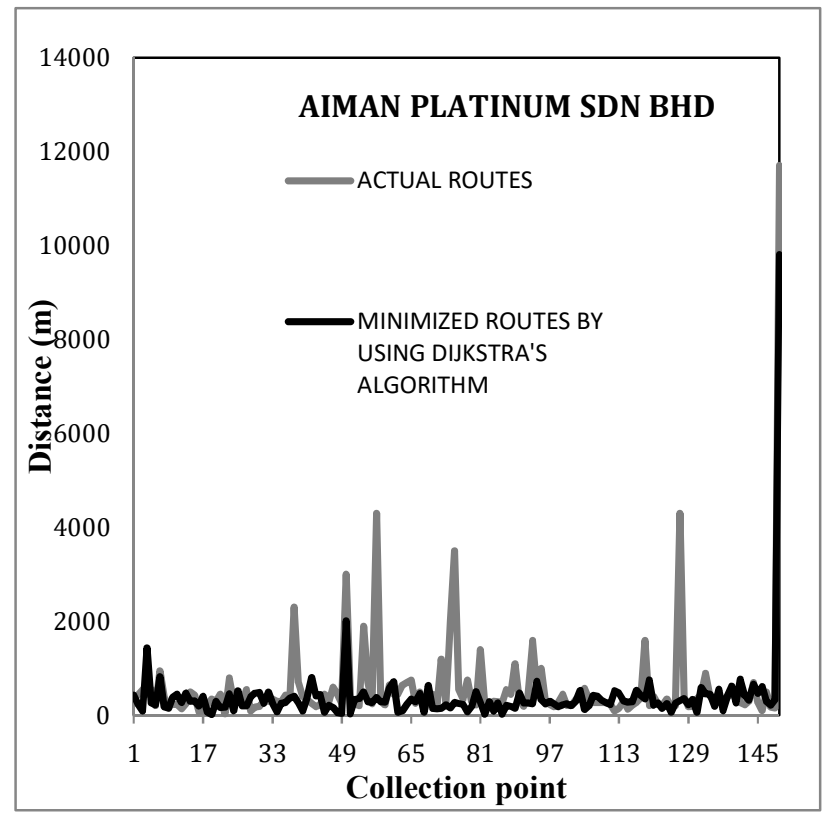

Fig.7. The difference between the actual and minimized routes of Contractor B

\section{Result 3: The reduction of Contractor C's routes $-12 \%$}

The collection routes that are digitized in the AutoCAD software, the total distance obtained is 20,754 meters for the MSW collection routes. The collection routes are minimized using Dijkstra's Algorithm and the shortest distance is obtained. Figure 8 shows the sequence of the collection points is also being changed to $1>2>3>4>5>6>7>8>9>16>17>$ $10>11>12>13>14>15>22>21>20>18>19>$ Transfer Station. The new MSW collection route is designed with the total of 22 collection points and one (1) Transfer Station without having any collection point unattended.

Fig. 8 shows the red lines indicating the new routes that were calculated using Dijkstra's Algorithm. The black dots indicate the collection points that are generated in the Google Earth software. The distance showings between the nodes are generated in the AutoCAD software after geo-referencing is made from Google Earth map. 


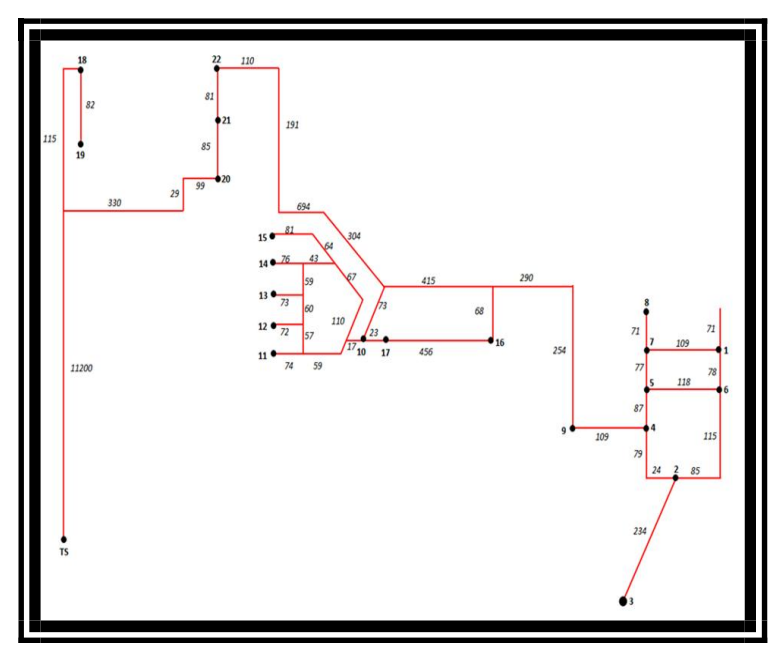

Fig.8. Simulated distance of MSW collection routes of Contractor C by Dijkstra's Algorithm

Fig. 9 shows the difference between actual and new routes of Contractor C. The actual routes are marked by grey lines and the optimized collection routes by Dijkstra's algorithm in black. The graph shows that the grey line was slightly higher compared to the black line. This indicates that the actual collection routes required longer distance compared to collection routes by the Dijkstra's algorithm.

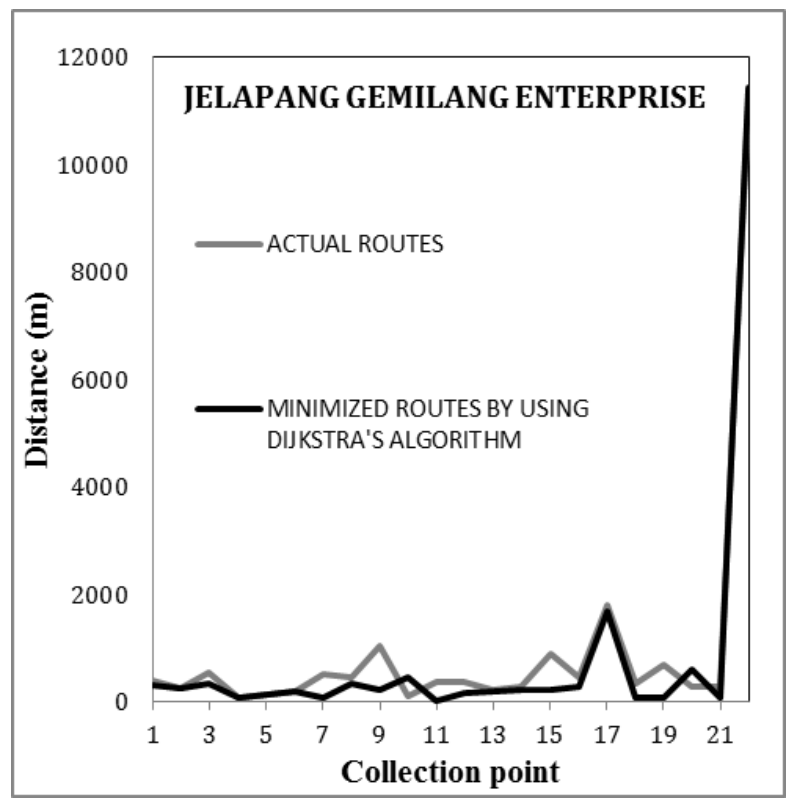

Fig. 9. The difference between the actual and minimized routes of Contractor $\mathrm{C}$ 
Overall, Fig. 10 below shows the longest reduction of collection distance is of Contractor B's, being 29,522 meter, which is from 87,773 meter to 58,521 meter (33\%). While the simulated distance of Contractor A was reduced from 26,708 meter to 22,259 meter (17\%). Thirdly, Contractor C's route was reduced from 20,754 meter to 18,281 meter (12\%).

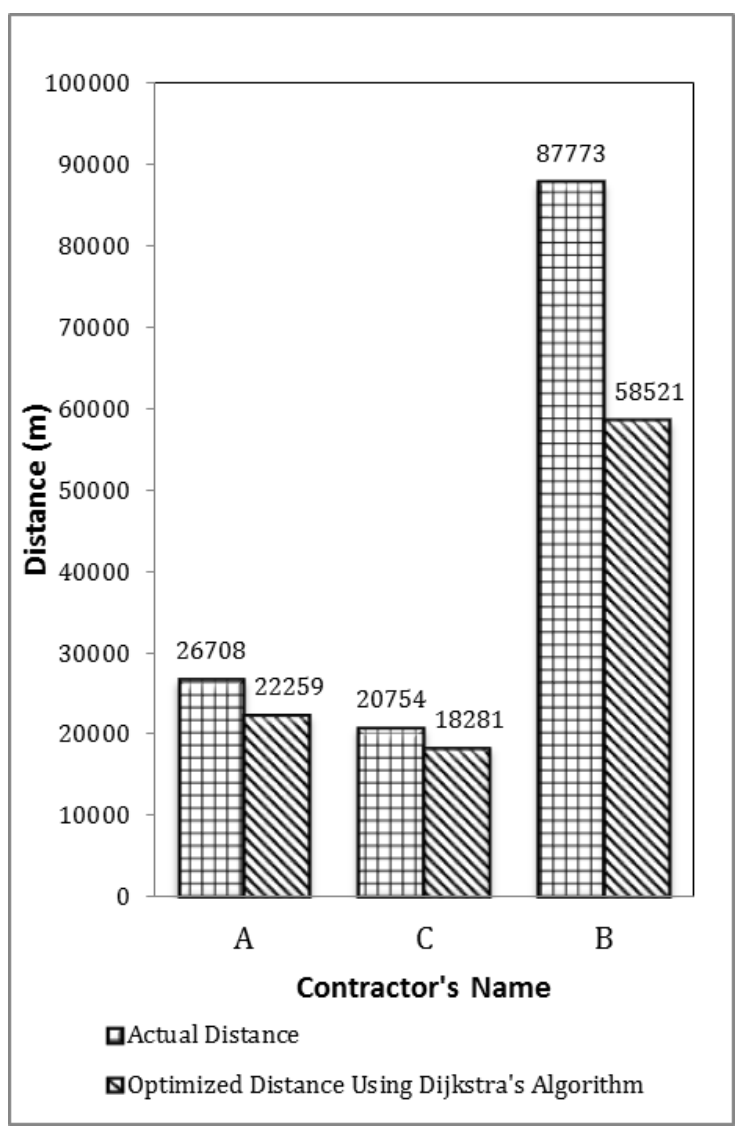

Fig.10. Comparison of actual distance and optimized distance for 3 Contractors by Dijkstra's

$$
\text { Algorithm }
$$

The results of this research concur with those of [10]. They showed that the simulation of new routes using the mathematical model of Dijkstra's Algorithm is reliable to produce the shortest, or the optimized distance of collection routes [10]. As in [6], this paper investigated the optimization of shortest routes of collection without taking into account the presence traffic congestion and traffic lights. Although in the real situation there are many intertwined factors to be considered in the efficiency of waste collection, it is theorized that the choice of the shortest distance will be able to contribute to the reduction of fuel consumption of the 
authorities involved in the waste management. The common practice of the municipals to save time and cost of collection is by collecting the solid waste early in the mornings or off peak hours. Hence, combining the off peak hours collection with these newly simulated routes would increase the cost effectiveness of the MSW.

The minimization of MSW collection routes distance can reduce the travelling time for the collection, which use lesser fuel consumption and promotes green environment as shorter distance is required to pick up the solid waste [11] [12]. Less travelling time is directly proportional to the low amount of harmful gases released to the atmosphere from the collection truck. In general, the optimization and minimization of the municipal solid waste collection routes, can save major cost in solid waste management and will indirectly save the environment [8].

The data obtained from this research too can be further investigated using other approach such as the ESRI ArcGIS software Geographical Information Systems (GIS). It is also a useful and resourceful tool in providing treatment, handling and visualization of spatial data [4]. Parameters such as travelled time, fuel consumption, pollutant emission such as carbon dioxide, types of collection vehicle, volume of solid waste generated at the collection points should be considered for better results [6].

\section{CONCLUSION}

It is concluded that this research has been able to produce the optimization of solid waste collection routes in Shah Alam, Malaysia by Dijkstra's Algorithm thus fulfilling the objective of reducing the distance of the routes. The results presented the realization that there is a shorter route than the municipal-prepared route plans in its waste collection. They also can expand the knowledge in the handling of solid waste management system, thus assisting the municipals of the area concerned to improve their societal service.

It is always noted that there are multiple factors in the efficiency of waste collection. Having found the shorter routes, the time required to collect garbage collection can be minimized. The unit time (haul time) is an important contribution in the calculation of handling solid waste management system. Here, the shortest path provided by this algorithm, may have contributed to a bigger volume of garbage collection, time-saving and truck fuel. The route 
travelled by the waste collectors, acting as markers for the efficiency of waste collection in an area, is consistent with the theory of unit time required in performing each tasks for collection systems.

While a shorter route is not a definitive indicator, it is nonetheless a good indicator. Generally, a shorter route reduces individual differences in fatigue and stress when working. In this case it is worthy to look into another factor, that is of human, of the fact that waste collectors are mainly dealing with dirt, of which not many would like to work in the sector. A further may combine parameters of a shorter path with human temperament to seek if this can be an inducer for better efficiency. It is overserved that manual work, such as collecting garbage, and low temporal decrement in work plays a role in the quality of effort. Hence, the predictor which can be researched is if there is any relationship between shorter routes and the less predictive factor, human behaviour, has the capacity to improve unwanted solid waste collections. In the same vein, further research too can be conducted in larger cities in the world by including more and different parameters.

\section{ACKNOWLEDGEMENTS}

The authors gratefully acknowledged the support from the Shah Alam City Council (MBSA) for providing the data. The authors would also like to thank the Research Management Institute, Universiti Teknologi MARA, Shah Alam Malaysia for the financial support.

\section{REFERENCES}

[1] Desa A, Abd Kadir N, and Yusooff F. Environmental awareness and education: A key approach to solid waste management (SWM) - A case study of a University in Malaysia, waste management - an integrated vision. In L. F. M. Rebellon (Ed), InTech, 2012, pp. $101-111$

[2] Fazeli A, Bakhtar F, Jahanshaloo L, Che Sidik N, and Esfandyari B A. Malaysia's stand on municipal solid waste conversion to energy: A review. Renewable and Sustainable Energy Reviews, 2016, 58, 1007-1016

[3] Ma J, Hipel K. Exploring social dimensions of municipal solid waste management around the globe - A systematic literature review. Waste Management, 2016, 1-10 
[4] Bhambulkar A, Khedikar I. Municipal solid waste (MSW) collection route for Laxmi Nagar by geographical information system (GIS). International Journal of Advanced Engineering Technology, 2011, 2(4):1-6

[5] Welivita I, Wattage P, and Gunawardena P. Review of household solid waste charges for developing countries - A focus on quantity-based charge methods. Waste Management, 2015, $46: 637-645$

[6] Billa L, Pradhan B, and Yakuup A. GIS Routing and Modelling of Residential waste collection for operational management and cost optimization. Pertanika Journal Science \& Technology, 2014, 22(1):193-211

[7] Bonomo F, Duran G, Larumbe F, and Marenco J. A method for optimizing waste collection using mathematical programming: A Buenos Aires case study. Waste Management \& Research, 2012, 30(3):311-324

[8] Tchobanoglous G, Theisen $\mathrm{H}$, and Vigil S A. Integrated solid waste management engineering principles and management issues. In P. H. King, \& E. Rolf Eliassen (Eds.), New York: McGraw-Hill International Editions, 1993

[9] Xie W C, Chen C M, Fan S S, and Li L L. A vehicle routing optimization method with constrainst condition based on max-min ant colony algorithm. Applied Mathematics \& Information Sciences, 2014, 8, 239-243

[10] Liu X Y, Chen Y L. Application of djikstra algorithm in logistics distribution lines. In Proceedings of the $3^{\text {rd }}$ International Symposium on Computer Science and Computational Technology, 2010, 48-50

[11] Malakahmad A, Putri M B, Munirah R M, and Noordiana K. Solid waste collection routes optimization via GIS techniques in Ipoh city, Malaysia. Procedia Engineering, 2014, $77: 20-27$

[12] Faulin J, Juan A, Lera F, and Grasman S. Solving the capacitated vehicle routing problem with environmental criteria based on real estimations in road transportation: A case study. Procedia Social and Behavioral Sciences, 2011, 20, 323-334

\section{How to cite this article:}

Norhafezah K, Nurfadzliana A H, Megawati O. Simulation of municipal solid waste route optimization by dijkstra's algorithm. J. Fundam. Appl. Sci., 2017, 9(5S), 732-747. 